Igor MAHER

Leon GOSAR

Slavko MEZEK

Manca PLAZAR MLAKAR

\title{
Prostorski informacijski sistem v programu CAMP Slovenija: podatki in metapodatki
}

S prostorskimi podatki se danes posredno ali neposredno ukvarjajo država, lokalne skupnosti, podjetja, številne vladne in nevladne organizacije, društva in druge neformalne skupine. Javnost želi in mora biti obveščena, kaj se dogaja v prostoru, $\checkmark$ katerem živi, kateri projekti in aktivnosti se dogajajo, in ob tem s svojim mnenjem in aktivnostmi vplivati na čim bolj kakovostno bivanje v prostoru. Informacije, povezane s prostorom in prostorskimi projekti, so razpršene. Tudi učinkovita izmenjava informacij med občinami in državnimi upravnimi organi se še ne izvaja.

Prostorsko načrtovanje je multidisciplinarna dejavnost $z$ veliko sodelujočimi področji in ravnmi. Za uspešno delovanje $v$ prostorskem načrtovanju je treba zagotavljati učinkovito sodelovanje med vsemi nosilci urejanja prostora - med državo in lokalnimi skupnostmi, med posameznimi organi državne uprave ter med lokalnimi skupnostmi samimi. V procesu prostorskega načrtovanja je zato izredno pomembna izmenjava informacij, kar pa je mogoče le z dobrim sistemom za njihovo zbiranje in posredovanje.
Today spatial data is directly or indirectly dealt with by states, local communities, companies, numerous government and non-government organisations, societies and other informal groups. The publics demand to be informed and have to be informed about spatial occurrences in their living environment, which projects and activities are underway and subsequently voice their opinions and act to affect quality improvements in space. Information tied to space and physical projects is dispersed. Even efficient interchange of information between government and municipal authority is not practised.

Spatial planning is a multi-disciplinary activity, with numerous participating disciplines and levels. Successful activity in physical planning needs efficient cooperation between all responsible parties involved in physical planning - the state and local communities, independent governmental departments and the local communities themselves. Exchange of information is crucial for the process of physical planning, but can be enabled only with a good system for information gathering and delivery.

\author{
Prostorski \\ podatki \\ Metapodatki \\ Prostorski \\ informacijski \\ sistem \\ Prostorsko \\ načrtovanje \\ CAMP \\ Spatial data \\ Meta-data \\ Spatial \\ information \\ system \\ Spatial planning \\ CAMP
}

\section{Uvod}

V Sloveniji v takšni ali drugačni obliki potekajo številne dejavnosti, projekti in operativne naloge, ki za uspešno izvedbo potrebujejo podatke različnih oblik in številnih virov. Pri tem so podatki zelo različni in se vrstijo od enostavnih statističnih tabel, raznih pisnih virov do prostorskih podatkov. S spletom se je dostop do njih bistveno poenostavil. Na prvi pogled nam sodobne tehnologije in dostop do številnih različnih podatkovnih in informacijskih virov močno olajšajo vsakdanje delo, v resnici pa odpirajo številne praktične težave in posledično nepravilno uporabo podatkov, napačno interpretacijo in zato lahko tudi napačne informacije.

V letu 2003 je bil podpisan sporazum med Ministrstvom za okolje, prostor in energijo, Mediteranskim akcijskim planom in predstavnikom občin južne primorske regije o izvedbi projekta Program upravljanja z obalnim območjem - CAMP. Program se izvaja v okviru Mediteranskega akcijskega plana (MAP), ki je usmerjen $v$ trajnostno upravljanje obalnega območja, ki združuje skrb za okolje in razvojno planiranje. CAMP Slovenija (http://camp.rrc-kp.si) skupno izvajajo MAP - Mediteranski akcijski program, Republika Slovenija in občine južne Primorske. Glavni projekt 
programa CAMP je priprava Regionalne zasnove prostorskega razvoja južne Primorske, kar je eden najpomembnejših projektov v Regionalnem razvojnem programu za južno Primorsko. Gre za temeljni prostorski strateški dokument območja, ki bo vplival na značaj (prostorskega) razvoja $\mathrm{v}$ regiji, s tem pa tudi na trajnostni razvoj območja, zato so kakovostni podatki ključnega pomena za rezultate projekta. V sklopu projekta se izvajata tudi podprojekt Analiza razpoložljivih podatkov ter izvedba promocijskih aktivnosti za Prostorski regionalni informacijski sistem - PRIS

S tem namenom se želi vzpostaviti enoten medmrežni portal PRIS, v katerem bodo združeni podatki in informacije, ki nastajajo v procesu prostorskega načrtovanja oziroma so v njem potrebni. PRIS naj bi omogočal zbiranje, uporabo in izmenjavo tako, da bo spodbudil in omogočil boljše sodelovanje med vsemi akterji v procesu prostorskega načrtovanja. Zato je načrtovan tako, da bo omogočal pregled in obvladovanje dogajanja v prostoru, pregled nad razpoložljivimi podatki in možnostmi za njihovo uporabo ter zagotavljal hiter in enostaven dostop do njih.

\section{Projekt PRIS - Prostorski regionalni informacijski sistem}

Projekti CAMP Slovenija potrebujejo številne podatke. Ker smo se že pri vzpostavljanju programa zavedali problematike pridobivanja in izmenjave podatkov v praksi, pri CAMP Slovenija izvajamo tudi podporni horizontalni projekt Prostorski regionalni informacijski sistem PRIS, kjer smo si zadali naslednje osnovne naloge:

- vzpostaviti infrastrukturo, ki bo omogočala organizacijo, zbira- nje in vzpostavljanje razpoložljivih prostorskih podatkovnih baz na regionalni ravni;

- vzpostaviti funkcionalno in vsebinsko povezavo s sorodnimi projekti na regionalni in državni ravni;

- zagotoviti podatkovne baze, prostorske podatke, bazo znanja končanih prostorskih projektov in druge informacije in jih $\mathrm{v}$ informacijskem sistemu PRIS ponuditi na razpolago lokalnim skupnostim, različnim organizacijam in širši javnosti;

- vzpostaviti sistem racionalnega pridobivanja in izmenjave podatkov o prostoru na vseh ravneh in vzpostaviti relevantni metapodatkovni sistem (podatki o razpoložljivih podatkih) v skladu z evropskimi standardi;

- zagotoviti usklajenost in povezavo s sistemom zbirk prostorskih podatkov (SZPP), ki ga vzpostavlja Ministrstvo za okolje, prostor in energijo, kar bo omogočilo tudi poznejšo dejansko podatkovno in funkcionalno povezavo.

Projekt tako neposredno izpolnjuje bistvene cilje CAMP Slovenija, saj bo: - operativno dolgoročno povezal in vzpostavil sodelovanje občin in države na področju upravljanja slovenske obale in njenega porečja. S sodobno tehnologijo in dogovorjenimi pravili za izmenjavo v projektu opredeljenih prostorskih podatkov bo olajšal prostorsko načrtovanje, pocenil pridobivanje in izmenjavo podatkov, javnosti s spremljanjem predpisanih kazalcev predstavil aktivnosti in projekte, ki se izvajajo na področju upravljanja prostora;

- povečal sposobnost lokalnih in regionalnih oblasti pri razvoju, predvsem pri načrtovanju, saj bo zaradi združenih podatkovnih baz o okolju bistveno povečana učinkovitost institucij, ki se ukvarjajo $\mathrm{Z}$ načrtovanjem $\mathrm{v}$ prostoru, varovanjem okolja, turizmom, varovanjem morja in njegovega povodja, varnostjo na morju, v prometu itd. Različne institucije bodo imele v skladu Z možnostmi informacijskega sistema PRIS in razpoložljivih podatkovnih baz vpogled v stanje prostora na območju regije.

\subsection{Analiza tehničnih možnosti vključitve podatkov v PRIS}

PRIS kot informacijski sistem ne bo omogočal produkcije novih podatkov, le prikaz izvedenih podatkovnih struktur različnim ravnem uporabnikov. Analiza tehničnih možnosti vključitve podatkov v PRIS opredeljuje vsebinske in tehnične naloge. Naloge, opisane $\mathrm{v}$ nadaljevanju, zaokrožujejo tako začetne korake kot tudi nadaljevanje oz. uporabo PRIS.

\section{Definiranje tehničnih standardov}

Definiranje tehničnih standardov za izmenjavo oz. dostope do podatkov je pomembno, saj se povezujejo podatkovne baze različnih formatov in prostorske ločljivosti. Zato ni nujno, da bi bili podatki že zdaj v takšnih tehničnih standardih, ki bi že v osnovi omogočali združevanje in vpogled. Zaradi različnih formatov zapisa izvornih podatkov se bo moral PRIS prilagoditi izvornim formatom posameznih podatkovnih baz in opredeliti postopke konvertiranja $\mathrm{v}$ formate, predpisane $\mathrm{v}$ tehničnih standardih sistema PRIS.

\section{Vzpostavitev pogojev za izmenjavo podatkov}

V Sloveniji na področju pridobivanja in izmenjave podatkov ni enotnega postopka in pravnih pogojev. Pravni pogoji so delno že vzpostavljeni s predpisi, ki urejajo dostop do informacij javnega značaja. Podrobneje pa bo šele izvajanje Uredbe o vsebini poročila o stanju na področju urejanja prostora ter minimalnih enotnih kazalnikih (Ur. 1 . RS 107/2004) opredelilo pogoje izmenjave podatkov za področje sta- 
nja $\mathrm{v}$ prostoru. Izvajajo se poglobljeni pregledi podatkovnih struktur in motivacija lastnikov in producentov podatkov za ureditev sistemov izmenjave podatkov.

\section{Postopki identifikacije in vzpostavitev podatkovnih baz v sistemu PRIS}

Postopki identifikacije in vzpostavitve podatkovnih baz $\mathrm{v}$ sistemu PRIS se nanašajo na dejavnosti za praktični preizkus zapisanih tehničnih standardov in pogojev za izmenjavo podatkov, saj bodo podatkovne baze povezane $\mathrm{v}$ sistem PRIS, kar pa ponovno pomeni proces in ne enkratnega dejanja. Izvajanje v skladu s tehničnimi standardi predvidene transformacije in instalacije podatkov se bodo dopolnjevale $v$ skladu s potrebami. Instalirane podatkovne baze morajo imeti nujno zapisan kratek zapisnik s postopki in opombami o zaznanih razlikah med dejansko proceduro in v tehničnih standardih opredeljeno proceduro.

\section{Vzpostavitev portala PRIS}

Pri vzpostavitvi portala PRIS gre za dve ločeni skupini dejavnosti:

- vzpostavitev tehnične infrastrukture sistema PRIS in vzpostavitev temeljne programske infrastrukture sistema PRIS (slika 1),

- vzpostavitev strokovne ekipe, ki upravlja tehnično in programsko infrastrukturo PRIS, ter vzpostavitev strokovne ekipe, ki vsebinsko upravlja podatkovne strukture in jih vsaj v začetnem obdobju tudi interpretira uporabnikom PRIS.

Velika prednost pri vzpostavitvi sistema PRIS je razpoložljivost večine temeljne tehnične opreme. RRC Koper je s projektom PHARE za potrebe informacijske podpore delovanja regionalne mrežne razvojne strukture pridobil informacijsko opremo, ki bo zdaj osnova tudi za projekt PRIS. Pretežni del programske opreme temelji na lastnem razvoju na podlagi odprtokodnih rešitev (Linux, MapServer, Horde, ipd.).

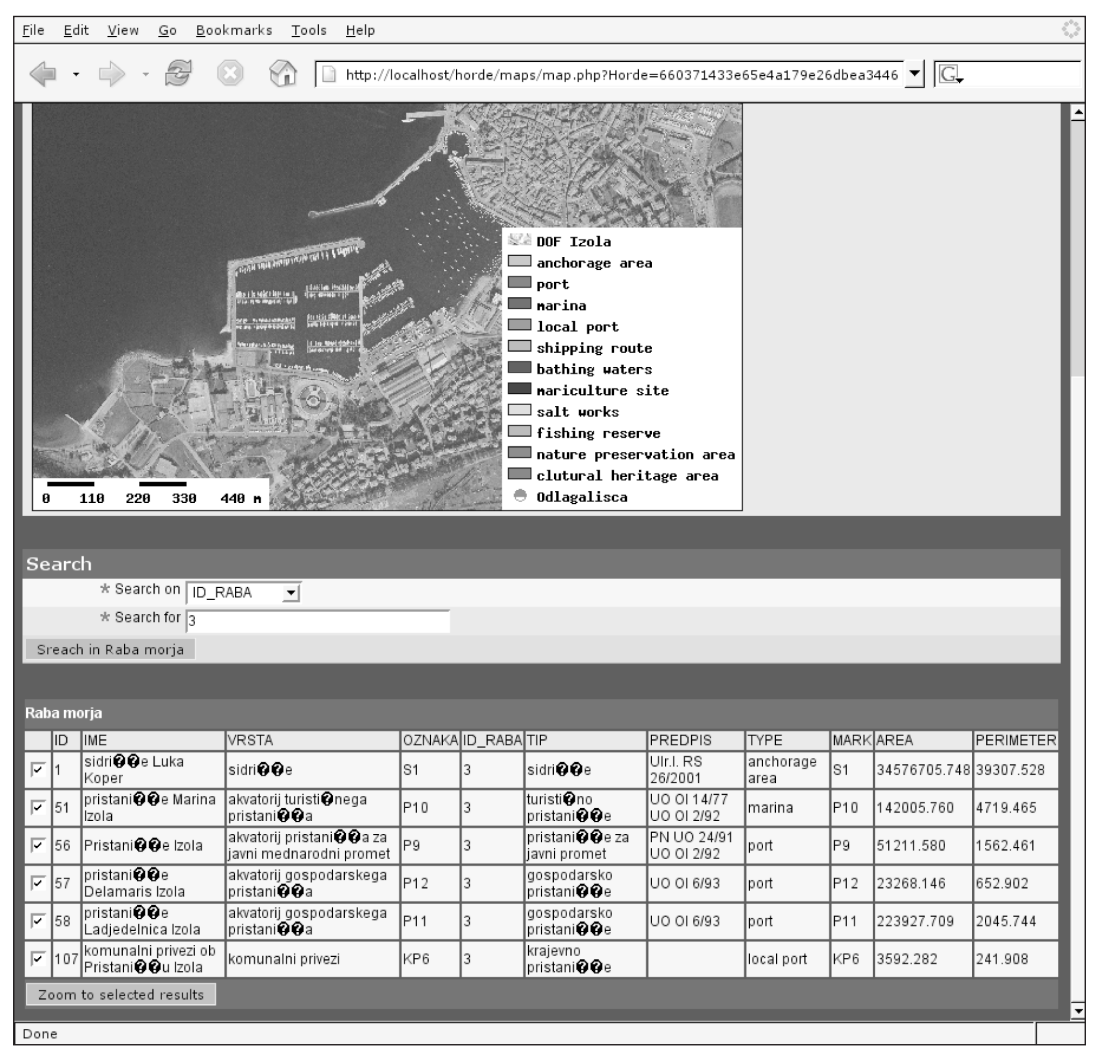

Slika 1: Prostorski podatki na medmrežnem portalu PRIS.
Sistem PRIS v osnovi temelji na naslednjih vsebinskih in tehničnih funkcionalnostih:

- prikaz stanja v prostoru na podlagi presekov skozi prostorske baze,

- zbirki podatkovnih baz, dokumentov, projektne dokumentacije in informacij, povezanih s prostorom prek enotnega internetnega portala PRIS,

- projektni del portala PRIS za promoviranje projektov, ki jih izvajajo občine, druge organizacije, podjetja in država $\mathrm{v}$ tem prostoru,

- povezave s podatkovnimi bazami državnih organov na tehničnem in vsebinskem področju, kjer bo mogoče,

- vizualni vpogled $\mathrm{v}$ prostorske okoljske podatke (internetni dostop do podatkov GIS) v obliki tematskih kart, map, planov in načrtov,

- interaktivna gradnja količine informacij, ki jih želi uporabnik pregledovati.

\section{Vzpostavljanje metapodatkovnega sistema PRIS}

Med analizo tehničnih možnosti za vključitev podatkov v PRIS se uvrščata tudi gradnja in vzpostavljanje metapodatkovnega sistema (t. i. podatki o podatkih). Osnova za gradnjo metapodatkovnega sistema je evropski standard $\mathrm{za}$ opis prostorskih podatkov CEN/TC 287, ki je v Sloveniji že uveljavljen. Metapodatkovni sistem mora omogočati stalen vpogled $\mathrm{v}$ metapodatke prek medmrežnega portala PRIS, kjer bodo opisane in vodene vse temeljne značilnosti razpoložljivih podatkovnih baz. Uporabljene formate metapodatkovne baze pa mora biti mogoče izvoziti v standardu XML, kar bo omogočalo enostavno prenašanje in uporabo metapodatkovne baze tudi v drugih informacijskih sistemih. 


\section{Metapodatkovni sistem PRIS}

V zadnjih letih se v strokovni domači in tuji literaturi pojavljajo številni članki na temo metapodatkov. Pri tem se uporabljajo različne definicije za metapodatek; od enostavnih, da so to podatki o podatkih, do kompleksnejših definicij, ki poskušajo uvrstiti pomen metapodatkov v posamezna specifična vsebinska področja.

\subsection{Zakaj metapodatki?}

Najsplošnejša definicija metapodatkov je, da vsebujejo podatke o podatkih; obsegajo podatke, ki se nanašajo na vsebino, strukturo, kakovost, lastništvo, distribucijo, tehnologijo, namen, uporabnost in druge elemente, ki so pomembni za pravilno interpretacijo oziroma uporabo podatkov. Metapodatkovne sisteme kot urejene podatkovne baze, grajene na podlagi enega izmed številnih razpoložljivih standardov, najpogosteje srečujemo $\mathrm{v}$ geoinformacijskih sistemih in knjižničnih informacijskih sistemih. Enostavne oblike metapodatkovnih sistemov so vgrajene tudi $\mathrm{v}$ vsakdanje pisarniške aplikacije za upravljanje dokumentov ali slik.

Uporaba metapodatkovnih baz se je v praksi zelo hitro začela ravno pri digitalnih prostorskih podatkih. Geoinformacijski sistemi klasičnim atributnim podatkom namreč podajo zelo pomembno novo dimenzijo - umestitev v prostoru. Pri tem lahko zelo hitro nastaneta popolnoma napačna končna informacija in interpretacija, saj je kakovost podatka $\mathrm{v}$ prostoru lahko omejena na območje države ali pa na centimeter natančno v prostoru. Na področju geoinformacijskih sistemov danes verjetno ni nikogar, ki bi preprosto uporabil prostorske podatke, ne da bi prej preveril in upošteval vsaj pripadajočih minimalnih metapodatkov. Metapodatki so torej nujno potrebni potencialnemu uporabniku za presojo, ali so podatki primerni za njegove potrebe in ali jih sploh lahko uporabi. Kot pričakovani minimum obsega metapodatkov mora biti podatek opisan vsaj $\mathrm{z}$ naslednjimi parametri:

- vsebina podatka,

- obseg v prostoru,

- koordinatni sistem,

- podatkovna struktura in tehnični format podatka,

- časovni okvir zajema podatka,

- pogoji uporabe ali pridobitve podatka.

Uporabniki pogosto potrebujejo še številne druge pomembne parametre, kot npr. kakovost in natančnost podatkov, njihovo popolnost, podrobno dokumentacijo in opis atributov podatkov ter omejitve uporabe.

Z dostopom do zmogljivih računalnikov in medmrežja so prostorski podatki dostopni vedno širšemu krogu uporabnikov (npr. ARSO - Atlas okolja, MapGoogle ipd.). Da bi jih lahko uporabljali, morajo o njih vedeti veliko več, kot so morali uporabniki pred leti. Uporabniki zato zahtevajo od producentov in lastnikov podatkov vedno več informacij in podatkov o samih podatkih. Ni pričakovati, da bi se ta trend ustavil.

\subsection{Metapodatki v Sloveniji}

Eden izmed prvih urejenih metapodatkovnih sistemov v Sloveniji je nastal leta 1997 na Ministrstvu za okolje in prostor (MOP) na področju prostorskih podatkov. Podatki v evidenci so bili prvotno pridobljeni leta 1997, s projektom GIS katalog 97. Na MOP so jih zbrali z anketiranjem izdelovalcev, upravljavcev in distributerjev prostorskih podatkov na območju Republike Slovenije. Rezultat anketiranja je bil seznam upravljavcev s kratkimi opisi njihovih podatkov, zbranimi v digitalni obliki. Opisi so vsebovali osnovni nabor informacij o podatkovnih nizih. Doslej je bilo izvedenih več dopolnitev, vendar je osnovna struktura metapodatkovnega opisa v Centralni evidenci prostorskih podatkov - CEPP ostala od leta 1998 nespremenjena in temelji na elementih standarda oz. specifikacije CEN TC/287. Za potrebe operativne rabe so $v$ CEPP spremenili vpogled $\mathrm{v}$ to podatkovno zbirko, ki zdaj temelji na trinivojski strukturi. Pregled vsebine metapodatka je tako poljudnejši in jasnejši ter bolje razumljiv posameznemu uporabniku. Deli se na tri ravni:

- kratek pregled - vsebuje zgolj informativne podatke o podatkovnem nizu $\mathrm{z}$ jasno grafično predstavitvijo, predstavljeni so elementi vsebine, določeni po specifikaciji Dublin Core;

- osnovni pregled - predstavljeni so vsi ključni elementi vsebine, kot jih pozna ISO TC211 - specifikacija za metapodatke ISO 19115;

- podroben pregled - predstavljeni so vsi elementi vsebine metapodatka po standardu CEN/TC287.

Razširitve obstoječih opisov na vsebino standarda in nove opise, ki so jih na MOP prejemali od producentov, so v bazo CEPP vnašali ročno vse do pojava orodja za podporo evidentiranju in dokumentiranju prostorskih podatkov MPedit, ki ga je GeoInformacijski center na MOP izdal konec novembra 1998. Hkrati z izdajo omenjenega orodja je vsak izmed producentov oziroma upravljavcev prejel kopijo svojih metapodatkovnih opisov v formatu orodja MPedit. Od takrat poteka ažuriranje baze CEPP izključno z izmenjavo dokumentov $\mathrm{v}$ formatu MPedit.

V zadnjih letih smo priča nastanku številnih bolj ali manj urejenih metapodatkovnih baz, od katerih se verjetno v praksi najbolj uporablja metapodatkovni sistem Statističnega urada RS - METIS, ki pokriva faze statističnega procesa od načrtovanja raziskovanj do diseminacije statističnih podatkov in metapodatkov. Nastal je na popolnoma drugačnih osnovah kot sistem CEPP in je $\mathrm{v}$ praksi tesno prepleten $\mathrm{v}$ delo SURS, saj me- 
tapodatki nastajajo v delovnem procesu v SURS od načrtovanja, raziskovanja pa vse do analize podatkov.

Ob boku dveh največjih metapodatkovnih sistemov v Sloveniji je nastala kopica različnih seznamov in evidenc, ki so se oblikovali v različnih državnih in paradržavnih institucijah. Najpomembnejše so $v$ Davčni upravi RS, Agenciji RS za javnopravne evidence in storitve ter nekaterih drugih agencijah različnih ministrstev. Njihov skupni imenovalec je, da so po strukturi različne, opisi podatkov pa praviloma niso $\mathrm{v}$ skladu $\mathrm{z}$ nobenim od standardov. Uporabniki tako v Sloveniji nimajo možnosti na enem kraju pridobiti niti osnovnega seznama, kakšne evidence in podatke imajo državni organi. Pri podatkih, ki jih vodijo in zbirajo javna podjetja ali zasebniki, je položaj še bistveno slabši.

S sprejetim Zakonom o dostopu do informacij javnega značaja (Uradni list št. 24/2003) se je položaj po eni strani uredil s stališča možnosti podaje zahtevka po izdaji take informacije in dolžnosti organa, da jo izda. V praksi se uporabnik še vedno srečuje $z$ razdrobljenostjo katalogov informacij javnega značaja, ki so v domeni posameznih organov in služb in niso zbrani na enem mestu. To pomeni, da mora uporabnik dobro poznati razmere, kateri podatki obstajajo in kdo je odgovoren za izdajo, saj jih je sicer skoraj nemogoče najti.

\subsection{Metapodatkovni standardi v Sloveniji}

V začetku leta 1999 je Urad za standardizacijo in meroslovje RS sprejel standard CEN/TC287 kot uradni standard za prostorske metapodatke v Republiki Sloveniji. Vzpostavljen je bil standardni izmenjevalni format za izmenjavo metapodatkovnih opisov kot naslednji korak pri razvoju in uveljavljanju metapodatkovnega standarda. Z brezplačno aplikacijo MP- edit sta omogočena predvsem večja odprtost metapodatkovnega sistema MOP/GIC in poenostavitev vzdrževanja. Mogoča pa sta tudi samostojno oblikovanje in nadgradnja svojega metapodatkovnega sistema na strani upravljavca podatkov po standardu MOP/GIC, ker standardni izmenjevalni format metapodatkovnih opisov temelji na standardu XML (XML je univerzalni format, namenjen opisu strukturiranih dokumentov in podatkov na medmrežju). Danes CEPP upravlja Geodetska uprava RS, pri kateri deluje Geoinformacijski center.

Pomemben temelj metapodatkovnega sistema CEPP je specifikacija Dublin Core (DC). DC sicer ni standard, temveč mednarodna pobuda na področju metapodatkovnih opisov in ima zelo široko sektorsko podporo pri uporabi na različnih področjih. Namen specifikacije Dublin Core ni bil nikoli nadomestiti ozko specificiranih standardov za področje metapodatkov, kot je na primer zelo podroben metapodatkovni standard za prostorske podatke ISO 19115. Namen DC in njegova vrednost sta ravno $\mathrm{v}$ dopolnjevanju s takšnimi specializiranimi standardi, saj tako pomaga uporabnikom pri odkrivanju in iskanju prostorskih podatkovnih nizov na različnih področjih in sektorjih. Torej gre za nekakšno skupno metapodatkovno jedro, ki je prenosljivo in razumljivo $\mathrm{v}$ posameznih specifičnih okoljih. V praksi se lahko učinkovito uporablja tudi za opis podatkov, ki nimajo prostorske dimenzije.

Ker je metapodatkovni sistem na Statističnem uradu RS nastajal zaradi drugačnih zahtev in potreb, temelji na drugih metapodatkovnih standardih in priporočilih. Zaradi mednarodne primerljivosti podatkov statistični uradi v EU večinoma uporabljajo skupno dogovorjene metodologije raziskovanj, obračunavanj in načela objavljanja statističnih agregatov, ki temeljijo na priporočilih Združenih narodov (United Nations, 1995, in UN/ECE, 1998).

\subsection{Projekt CAMP Slovenija in podatki}

Pomemben končni uporabnik rezultatov CAMP Slovenija so občine. Stanje poznavanja in uporabe podatkov in informacij $\mathrm{v}$ občinah južne Primorske je zelo različno. Nekatere zbirajo in vlagajo v različne prostorske podatke že vrsto let, gradijo svoje metapodatkovne sisteme in so aktivni uporabniki vseh infrastrukturnih prostorskih podatkov, ki jih lahko na državni ravni pridobijo. Nekatere manjše občine nimajo niti ustrezne infrastrukture za uporabo ali analizo podatkov in posledično ne poznajo razpoložljivih možnosti.

Analiza potrebnih podatkov za Prostorski informacijski sistem je izvedena $\mathrm{z}$ vprašalnikom ter pogovori s predstojniki uradov in uradniki, pristojnimi za prostorsko načrtovanje. Osnova za oblikovanje vprašalnika je bil osnutek Uredbe o vsebini poročila o stanju na področju urejanja prostora ter minimalnih enotnih kazalnikih. Izvedeni vprašalniki in pogovori so po pričakovanjih prikazali velike razlike med posameznimi občinami na področju uporabe podatkov za potrebe prostorskega načrtovanja in poznavanja obstoječih potrebnih podatkovnih baz tako $z$ vidika vsebine kot $\mathrm{z}$ vidika razpoložljivosti.

Velika težava so podatki, pri katerih je pomemben časovni presek. Večina jih ni na razpolago neposredno, ampak so izvedeni iz statističnih in drugih razpoložljivih podatkov. Težava je povezana tudi s kadrovsko zasedbo na občinah, saj imajo le redke delovno mesto t. i. podatkovnega analitika statistika, ki takšne podatke pripravlja za potrebe prostorskega načrtovanja.

V zastavljeni projektni nalogi je bilo izvedeno tudi pisno naročilo različnih podatkov, ki so jih občine in izvajalci posameznih projektov CAMP Slovenija zahtevali ali potrebovali za izvajanje nalog. Namen 
naročanja je predvsem preveritev razpoložljivosti podatkov iz obstoječih operativnih evidenc, odzivnost posameznih organizacij na naročilo, pogoji pridobivanja in formati podatkov. Le nekaj organizacij je pospremilo izdajo podatkov z ustreznim metapodatkovnim opisom, kar je skrb vzbujajoče. Tudi $\mathrm{v}$ CEPP je večina vnesenih podatkov stara in jih lastniki niso ažurirali. Zanesljivost metapodatkovnih baz je izjemno pomembna tudi zato, ker jim večina manj izkušenih uporabnikov slepo zaupa.

Večina sodelujočih občin nima sklenjenih posebnih sporazumov o izmenjavi podatkov, ker zadnjih od javnih organizacij pogosto ne zahtevajo ali pa se izmenjava dogaja spontano oz. na zahtevo. V projektu smo za občine izdelali predlog sporazuma za izmenjavo podatkov, ki formalno urejuje odgovornosti in način izmenjave med občinami ter javnimi podjetji in nosilci javnih koncesij na lokalni ravni.

Praksa kaže, da so podatki pogosto $v$ različnih formatih. Namen sporazumov med uporabniki in producenti podatkov in tehničnega pravilnika je predvsem $\mathrm{v}$ tem, da občinam olajša formulacijo tehničnih standardov za izmenjavo podatkov, njihovih formatov in različnih drugih tehničnih pravil (topologija, koordinatni sistem, zahtevana natančnost ...) za posamezne vrste podatkov. Sprejeti tehnični pravilniki in sporazumi za izmenjavo podatkov pomenijo celovit in urejen pristop k aktivnejši izmenjavi in uporabi podatkov tako na občinah kakor tudi pri producentih podatkov.

\section{Sklepi}

Vse ciljne skupine $\mathrm{v}$ programu CAMP bodo $\mathrm{z}$ združevanjem prostorskih informacij veliko pridobile. Občine želijo in potrebujejo združevanje prostorskih podatkov in informacij. Združevanje podatkovnih baz pomeni racionalizacijo stroškov pridobivanja in izmenjave podatkov ter hitrejši pretok informacij. Vzpostavitev metapodatkovnega sistema zagotavlja transparentnost informacij o razpoložljivih osnovnih podatkih in o želenih dodatnih podatkih glede informacij o prostoru.

Občine po državni zakonodaji in direktivah EU morajo izvajati določene aktivnosti poročanja o stanju $v$ prostoru. Namen projekta PRIS in vzpostavitve ustreznega metapodatkovnega sistema je poenostavitev izvajanja teh aktivnosti. Delna avtomatizacija kakovostnega pridobivanja in izmenjave podatkov bo olajšala spremljanje stanja v prostoru ter ključnih kazalcev stanja v prostoru ter omogočala transparentno posredovanje informacij uporabnikom PRIS. Zavedati se je treba, da gradnja informacijskega sistema ni enkratno dejanje, temveč proces, ki se stalno nadgrajuje.

Igor Maher, univ. dipl. oec., Mestna občina Koper, Koper

E-pošta: igor.maher@koper.s

Mag. Leon Gosar, univ. dipl. inž. grad., Univerza v Ljubljani, Fakulteta za gradbeništvo in geodezijo, Katedra za mehaniko tekočin z laboratorijem, Ljubljana E-pošta: leon.gosar@fgg.uni-lj.si

Slavko Mezek, univ. dipl. inž. kraj. arh., Regionalni razvojni center Koper, Koper E-pošta: slavko.mezek@rrc-kp.si

Dr. Manca Plazar Mlakar, univ. dipl. inž. arh., Studio Mediterana, d. o. o., Izola E-pošta: manca.mlakar@gmail.com

\section{Literatura in viri}

Banovec, P., Gosar, L., Steinman, F. (1999) Coastal Zone Management Plan in Slovenia - Marine Area Uses, Environmental System Research Institute, User Proceedings from 14. ESRI European User Conference, Munich, Germany.

Burbridge, P. (1999) The Guiding Principles for a European ICZM Strategy, Towards a European Strategy for Integrated Coastal Zone Management (ICZM), University of Newcastle, UK.

Capobianco, M. (1999) EU Demonstration Programme on Integrated Coastal Zone Management, Role and Use of Technologies in relation to ICZM, Technomare S.p.A., Venezia, Italy.
ESDP - European Spatial Development Perspective (1999) Towards Balanced and Sustainable Development of the Territory of the European Union, European Commision, Luxembourg.

Gosar, L., Plazar Mlakar, M., Prešeren, T., Steinman, F. (2005) Functional connected areas in regional planning: sea and land uses interactions, CoastGIS: 6th International symposium on GIS and Computer Cartography for Coastal Zone Management: definig and building a marine and coastal spatial data infrastructure, Aberdeen, Scotland, UK, 21.-23. julij 2005.

King, G. (1999) EU Demonstration Programme on Integrated Coastal Zone Management, Participation in the ICZM Processes: Mechanisms and Procedures Needed, Hyder Consulting, Brussels.

The Influence of EU Policies on the Evolution of Coastal Zones (1999) Institute for European Environmental Policy, London, UK. 